\title{
A Forensic Analysis of a Fatal Fire in an Indoor Shooting Range using Coupled Fire and Evacuation Modelling Tools
}

\author{
ZHAOZHI WANG, FUCHEN JIA, and EDWIN RICHARD GALEA \\ Fire Safety Engineering Group \\ University of Greenwich \\ 30 Park Row, Greenwich \\ London SE10 9LS, U.K. \\ JUN-HO CHOI \\ Department of Fire Protection Engineering \\ Pukyong National University \\ 45 Yongso-ro, Nam-gu \\ Busan 48513, Republic of Korea
}

\begin{abstract}
In this paper, coupled fire and evacuation computer simulations are used to numerically reconstruct a fatal fire that occurred in an indoor shooting range in Pusan, Korea in 2009. Of the 16 building occupants, 15 were killed and only one survived with serious injuries. The analysis demonstrates that these modelling techniques can accurately reproduce the outcome of this fire. The numerical approach is then used to forensically analyse the incident to determine what factors significantly contributed to the high loss of life. In particular, the occupant response times are analysed as is the impact of the flame spread rate on the polyurethane foam cladded walls of the shooting range. The results suggest that it is unlikely that anyone could have survived if response times were greater than 5 seconds. Furthermore, the analysis suggests that fatalities could not have been completely avoided even if the occupants had zero response time. In addition, it is demonstrated that gunpowder residue on the polyurethane foam walls is the critical factor in producing the high loss of life in this incident. The average number of fatalities could be reduced from an average of 14.9 in the reconstruction case with gunpowder residue on the polyurethane foam walls to an average of 0.1 if the walls are completely free of gunpowder residue. However, to completely eliminate fire related casualties, it is necessary to use a polyurethane foam wall cladding material with low flame spread rates together with an effective gunpowder cleaning system.
\end{abstract}

KEYWORDS: fire investigation; forensics, shooting range fire; fire simulation; evacuation simulation; response time.

\section{INTRODUCTION}

On the 14th November 2009, a deadly fire occurred in an indoor shooting range in Pusan Korea, claiming the lives of 15 people [1,2]. The shooting range, located on the second floor of a five floor structure consisted of a large open space (shooting range) which had its walls and ceiling covered in polyurethane foam (PUF) which was used to dampen the ballistic noise. Adjacent to the shooting range was a lounge area (see Fig. 1). Just prior to the start of the fire, there were 16 people (12 male and 4 female) located within the premises, 4 in the shooting range and 12 in the lounge area. The fire was initially ignited in a corner of the shooting range where some balloons were stacked. The fire spread rapidly from the shooting range to the adjacent lounge, resulting in the death of 15 people and severely injuring one person who sustained burns to $45 \%$ of his body. The cause of the tragedy and the origin of the fire was investigated via experimentally studying the burning characteristics of the sound absorbing materials on the walls and analysing the closed-circuit television (CCTV) video clips recorded during the incident [2]. It was concluded that the rapid burning of the PUF on the walls was aided by accumulated gunpowder residue resulting in insufficient time being available for the occupants to escape. As a result it was recommended that to improve fire safety in indoor shooting ranges, gunpowder residue on the walls of the shooting range should be thoroughly removed. Furthermore, following the fire and the investigation, the shooting range was eventually reopened to the public after a gunpowder cleaning system was installed. 
This incident and the conclusions of the subsequent investigation raises two questions concerning survivability in this and similar incidents. The first question concerns the response time (also known as pre-movement time) of the occupants. The sole survivor was initially situated in the lounge, seated on a sofa. He started his evacuation when he felt a vibration under his feet and saw flames suddenly spewing out from the door to the shooting range into the lounge with a booming sound [2]. It is known that occupant response time is a critical factor in determining survivability in evacuations involving fire. The numerical reconstruction of an aircraft fire accident demonstrates that in fire scenarios where flashover occurs every second counts in determining survivability and delays of seconds can make the difference between life and death [3].

Given the nature of this incident it is natural to raise a question concerning the speed of response of the occupants and whether the number of fatalities could have been significantly reduced had the occupants responded quicker to the fire. In particular:

\section{Q1: Could all the occupants have escaped if they had started to evacuate as early as possible?}

The second question concerns the main recommendation from the fire investigation. Could the number of fatalities been significantly reduced had a gunpowder cleaning system been installed as recommended? Following this tragedy, the shooting range was renovated, a gunpowder cleaning system installed and the facility reopened. Could such a system prevent a similar tragedy? This leads to the second question:

\section{Q2: Could the large loss of life in this incident been completely avoided if the gunpowder residue had been completely removed from the walls in the shooting range?}

This study is an attempt to address these two questions. Firstly, the shooting range fire tragedy is reconstructed by undertaking a coupled fire and evacuation simulation using the computational fire engineering tools, buildingEXODUS [4] and SMARTFIRE [5]. Then the sensitivity of the occupant survivability to response time is analysed. Finally, the impact of the removal of the gunpowder residue from the walls on survivability is investigated.

\section{SHOOTING RANGE FIRE}

The indoor shooting range where the fire took place was located on the second floor of a five-story building [2]. From the entrance hall on the ground floor of the building, the indoor shooting range and its adjacent lounge could be accessed via a stair case. Depicted in Figure 1 is the floor plan of the geometry including the stair case, the lounge and the shooting range. The internal height of the shooting range was approximately $2.3 \mathrm{~m}$. The development of the fire in the incident and the evacuation process were recorded by the installed video cameras. Some key milestones of the fire development are listed in Table 1 . The fire started in the corner of the shooting range, $1.5 \mathrm{~m}$ from the first shooting booth, where some balloons were stacked. People inside the shooting range noticed the start of the fire within one second. At the third second, the door of the entrance to the shooting range was forced open by the high pressure generated by the rapidly developing fire and the occupants started to evacuate. Six seconds into the fire, heavy smoke spread out the entrance of the shooting range. About 9-11 seconds after the start of the fire, the cameras stopped working. The PUF cladding attached to the walls and ceiling inside the shooting range was the main contributor to the fire load. Although the fire lasted for only a short period of time, people inside the lounge and shooting range were exposed to high temperatures and heavy smoke, making evacuation difficult. In Fig. 1, the letter ' $F$ ' identifies the location where a fatality was found, while the letter ' $S$ ' indicates the final location of the only survivor. The survivor (who suffered burns to $45 \%$ of his body) was initially seated on the sofa in the lounge before the fire started. He felt vibration under his feet and saw flames suddenly spewing from the shooting range door into the lounge with a booming sound before he started to escape via the stairs. This person managed to exit the building before being rescued. Three other occupants managed to exit the building but eventually died of their injuries. The other 12 building occupants perished within the building, with two of these collapsing on the stairs. 


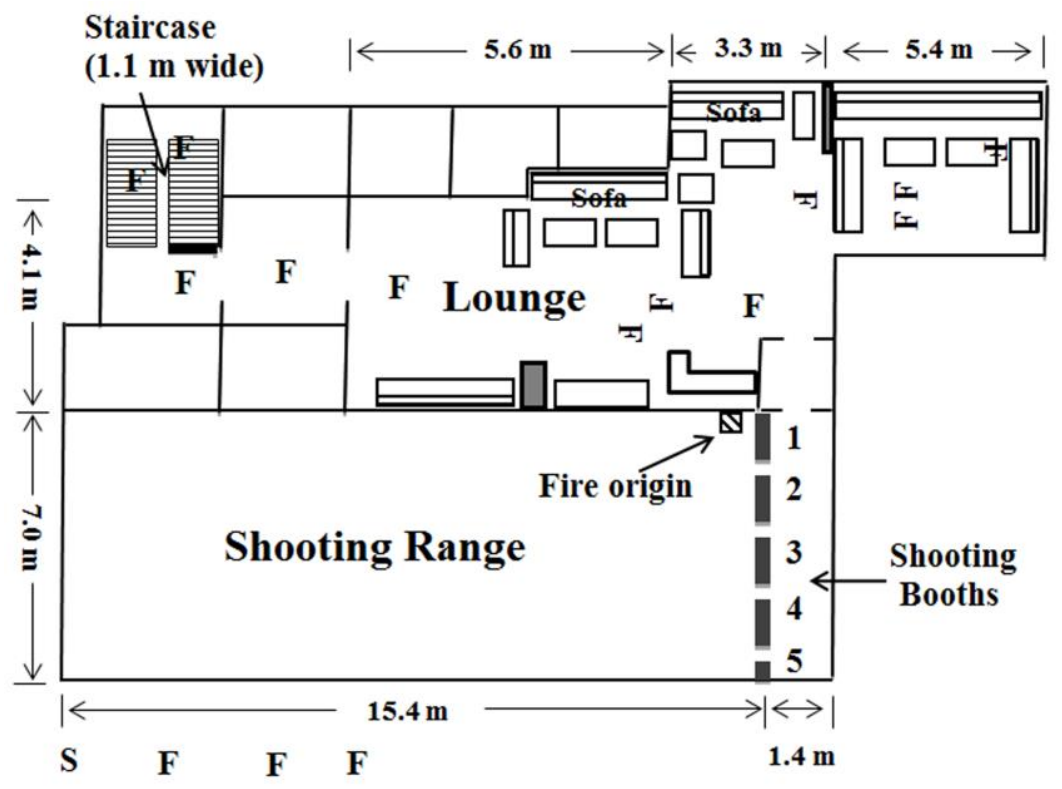

Fig. 1. Schematic of the fire floor and the locations of the victims, where ' $F$ ' indicates the location of a fatality and ' $\mathrm{S}$ ' indicates the location of the survivor.

Table 1. Events of the incident recorded from video images $[1,2]$.

\begin{tabular}{|c|l|}
\hline Time (s) & \multicolumn{1}{c|}{ Events } \\
\hline 0 & $\begin{array}{l}\text { Intense light occurred at 1.5 m in front of the first shooting booth; and the } \\
\text { fire started; }\end{array}$ \\
\hline 1 & $\begin{array}{l}\text { Strong fire and heavy smoke started pouring out at the first shooting } \\
\text { booth and visitors in the second and the third shooting booths turned their } \\
\text { heads toward the first shooting booth. }\end{array}$ \\
\hline 3 & $\begin{array}{l}\text { A powerful light reflected at the entrance of the shooting range; Intense } \\
\text { lights, flames and smoke were seen, and the wall of the doorway was on } \\
\text { fire; Visitors and staff started to evacuate. }\end{array}$ \\
\hline 6 & Smoke came out the entrance of the shooting range; \\
\hline $9-11$ & The flames were more intense and cameras failed. \\
\hline
\end{tabular}

\section{RECONSTRUCTION OF THE FIRE AND EVACUATION}

\section{Simulation Tools}

A research version of SMARTFIRE V4.1 is used to perform the fire simulations in this study. The SMARTFIRE software has been described in previous publications [3, 5-10] and so is not described in detail in this paper. The CFD engine in SMARTFIRE has many physics features that are required for fire field modelling, such as the multiple ray radiation model, the volumetric heat release model, the gaseous combustion model, smoke model, toxicity model, flame spread model, pool fire model and k-epsilon turbulence model. The flame propagation model [6], which is used to simulate the ignition of interior solid materials in the current analysis, plays an important role in successfully simulating the spread of fire. This model has been recently refined to minimise the mesh dependence of numerical predictions of flame spread over solid burnable surfaces [9]. In the fire analysis presented here the following hazards are predicted; temperature, smoke concentration (extinction coefficient), radiative flux, $\mathrm{CO}$ concentration, $\mathrm{CO}_{2}$ concentration, $\mathrm{HCN}$ concentration and $\mathrm{O}_{2}$ concentration. Note that the generation of irritant fire gases is not included in these simulations.

The buildingEXODUS evacuation model is used to perform the evacuation simulations presented in this paper [4]. The EXODUS software takes into consideration people-people, people-fire and people-structure 
interactions. It comprises five core interacting sub-models: the OCCUPANTS, MOVEMENT, BEHAVIOUR, TOXICITY and HAZARD sub-models. The OCCUPANTS sub-model describes an individual as a collection of defining attributes and variables such as name, gender, age, maximum unhindered fast walking speed, maximum unhindered walking speed, response time, agility, etc. The HAZARD sub-model controls the atmospheric and physical environment by importing the fire data, like those generated by the SMARTFIRE CFD fire model. The TOXICITY sub-model determines the physiological effects on an individual exposed to the toxic and thermal environment distributed by the HAZARD sub-model. This is determined using the Fractional Effective Dose (FED) and Fractional Irritant Concentration (FIC) concept [11]. Within buildingEXODUS two models are provided for the determination of the fractional effective dose of radiative heat, the so-called Pain Threshold model (in which the dose required to cause effect $\left(D_{r}\right)$ is $80 \mathrm{~s}\left(\mathrm{~kW} / \mathrm{m}^{2}\right)^{4 / 3}$, which is the equivalent to an exposure of $2.5 \mathrm{~kW} / \mathrm{m}^{2}$ for 24 seconds) and the Incapacitation model (in which $D_{r}=1000 \mathrm{~s}\left(\mathrm{~kW} / \mathrm{m}^{2}\right)^{4 / 3}$, the equivalent to an exposure to $2.6 \mathrm{~kW} / \mathrm{m}^{2}$ for 5 minutes which can result in a $1 \%$ mortality) [7]. The Incapacitation model is used in the calculations in this study. When an occupant moves through a smoke filled environment their travel speed is reduced according to the experimental data of Jin [12] which relates light extinction coefficient to walking speed. All these effects are communicated to the BEHAVIOUR sub-model which, in turn, feeds through to the movement of the individual. The behaviours in buildingEXODUS include crawling, climbing over seats, maintaining target exits, wayfinding, etc. In the coupled fire and evacuation analysis presented here the following fire related parameters are considered:

- Light extinction coefficient - related to walking speed using the Jin data [12] and whether the agent is walking or crawling.

- $\quad$ FIH - fractional incapacitating dose of heat, both radiative and convective (based on the Purser model described in [11]).

- $\quad$ FIN - fractional incapacitating dose of narcotic agents, which in this simulation include $\mathrm{CO}, \mathrm{CO}_{2}$, $\mathrm{HCN}$ and $\mathrm{O}_{2}$ based on the Purser model described in [11]).

An agent is considered incapacitated when the FED (either FIN or FIH) is equal to one. An agent is considered injured if their FED (either or both FIH or FIN) is greater than 0.1. The HAZARD sub-model of buildingEXODUS can read data generated by the SMARTFIRE CFD fire model. To transfer CFD fire hazard data the user must define a consistent set of zones within both the SMARTFIRE and EXODUS geometry. These zones are intended to represent regions in which the fire hazard data is expected to be near uniform i.e. exhibiting small spatial variation. The hazard data within SMARTFIRE is averaged over these zones to produce two values, a hazard value at a nominal head height and a value at a nominal knee height. Some applications of this coupled fire and evacuation simulation technique can be found in $[3,7,8]$.

\section{Fire Simulation and Results}

The geometry set up of the SMARTFIRE simulations for the shooting range fire is presented in Fig. 2. The PUF on the walls and ceilings made the largest contribution to the fire fuel followed by the seats and tables in the lounge area. The material properties of these fuels used in the fire reconstruction are given in Table 2. The burning behavior of the PUF with and without gun powder residue were experimentally studied as part of the investigation [2]. The flame spread rates were not measured but can be estimated from the experimental observations. For the foam with gunpowder residue, the fire spread from the ignition point at the bottom of the wall to the top of the $2 \mathrm{~m}$ high foam board in just one second. For the foam board without gun powder residue, it took 5 seconds for the fire to spread from the ignition point to a height of approximate $1 \mathrm{~m}$. The estimated flame spread rates based on these observations are presented in Table 2 and are used in the fire simulations. Some of the PUF far away from the fire origin is flame-resistant sound absorber. This flame-resistant sound absorber extinguished itself in the experiments when the source of ignition was removed. However, its burning characteristic with gunpowder residue is quite similar to that for the PUF listed in Table 2. As other properties of the PUF were not measured in [2], the data in Table 2 are the same as those of the sound absorber PUF used in the simulation of the Rhode Island nightclub fire [7]. The data in Table 2 for the sofa and tables are the same as those used in the simulation of a rail car fire [9]. As the fire spread very rapidly along the PUF surface and the tables and seats were ignited much later than the completion of the evacuation, the precision of their properties has negligible impact on the reconstruction of the incident. The HRRs (heat release rates) for the PUF, the tables, seats and wood 
columns are the same as those used in the Rhode Island night club fire simulation or the rail car compartment fire simulation respectively [7, 9].

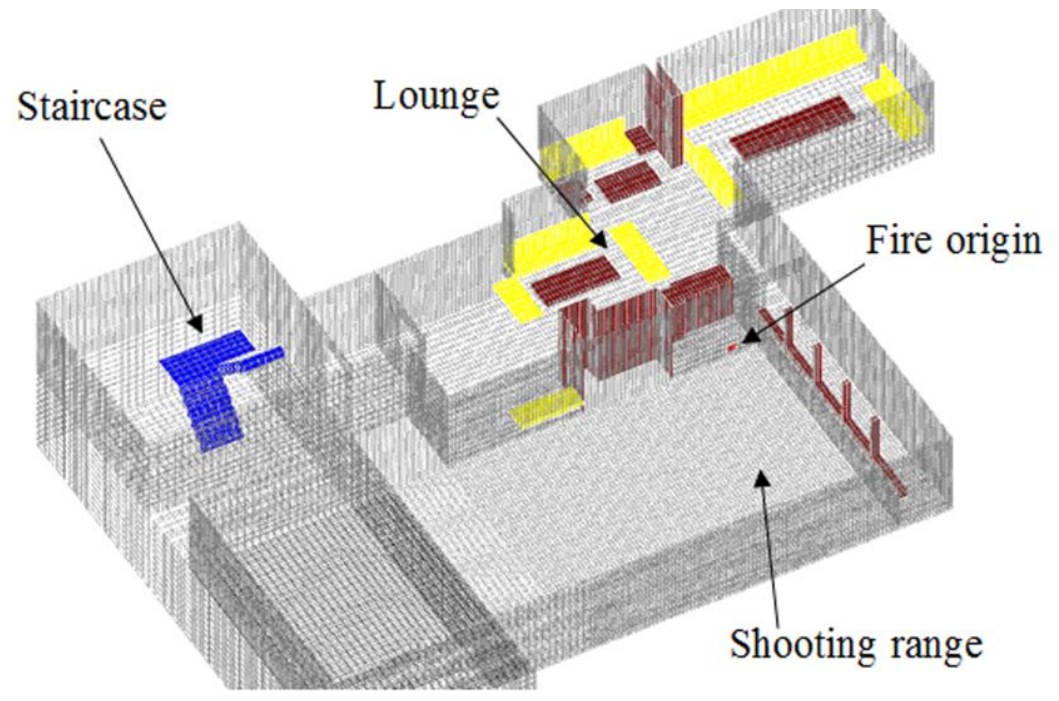

Fig. 2. Computational mesh used in the SMARTFIRE simulation.

Table 2. Material properties.

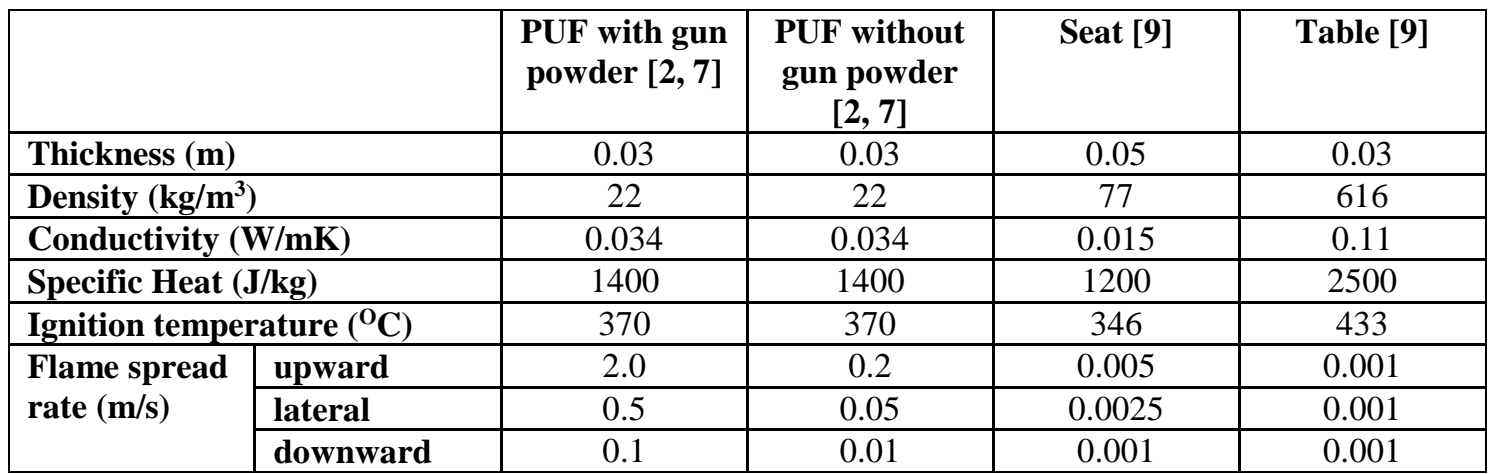

The eddy dissipation combustion model (EDM) [13] is used to simulate the burning of the combustible gases released from the ignited solid materials. The main fire fuel load in the shooting range fire was the wall PUF. For this reason, the gas phase reaction is specified to be the combustion of PUF. An average effective heat of combustion of $17.5 \mathrm{MJ} / \mathrm{kg}$ is taken for the PUF $\left(\mathrm{C}_{1} \mathrm{H}_{1.7} \mathrm{O}_{0.3} \mathrm{~N}_{0.07}\right)$ [14]. The parameters of the toxicity model for the calculation of $\mathrm{CO}, \mathrm{CO}_{2}, \mathrm{HCN}$ and $\mathrm{O}_{2}$ are those for the PUF in [7]. The multi-ray radiation model with 48 rays is used to represent thermal radiative energy exchange. At the start of the fire simulation a small segment of the wall, measuring $0.01 \mathrm{~m}^{2}$ is ignited. The location of the ignition point is identical to that in the incident. Due to the rapid flame spread rate over the PUF wall cladding, the precise size of the ignition area will not significantly impact the outcome of the simulation. Simulations are carried out with a time step size of 0.05 seconds.

Mesh quality is always crucial to any successful CFD fire simulation. Two mesh scenarios with computational cells of 393,399 and 663,822 respectively are used in the fire reconstruction with a time step size of 0.05 seconds. Figure 3 depicts the predicted HRRs in the fire reconstruction with the two different meshes. As seen in the figure, the predicted HRRs with the fine mesh and the coarse mesh are almost identical. The maximum relative difference of predicted HRRs between the two mesh scenarios is $10 \%$ at around 6-8 seconds. The mesh sensitivity study suggests that the mesh consisting of 393,399 cells is adequate for the fire reconstruction. As there is a need of simulating several scenarios in the investigation 
of the impact of flame spread on the fire development, the relative coarse mesh with 393,399 computational cells is adopted in this study.

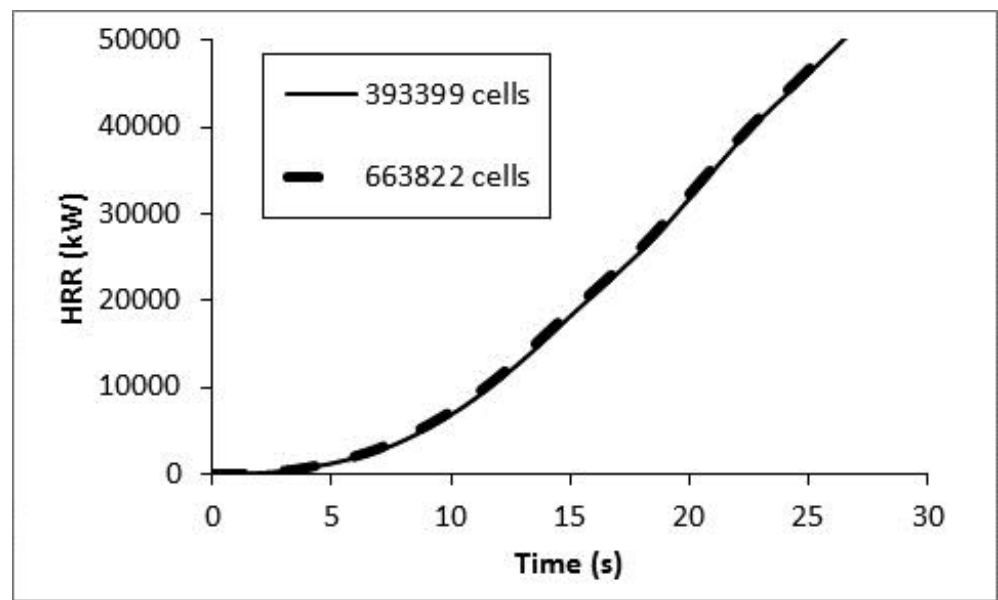

Fig. 3. Predicted HRRs in the fire reconstruction with different meshes.

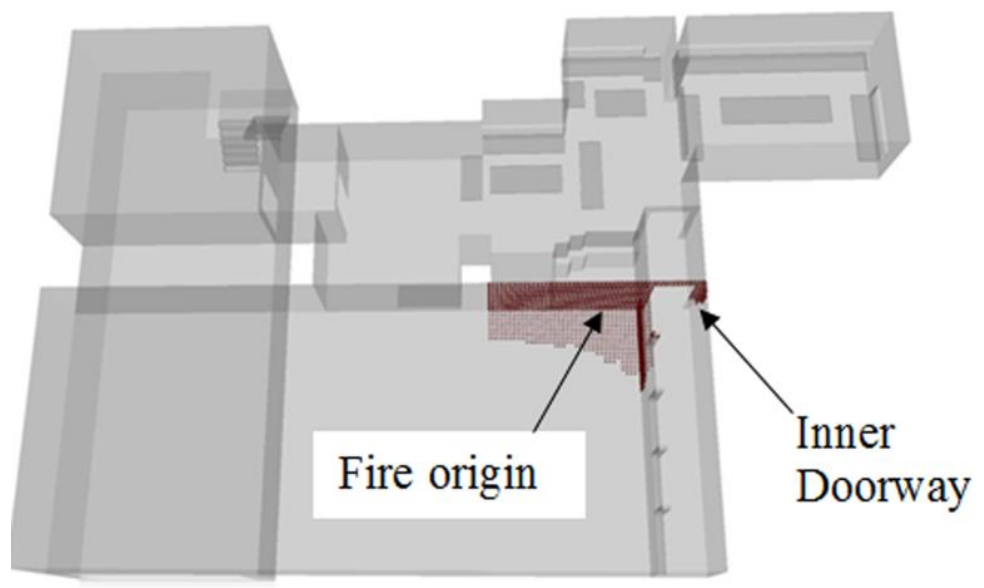

Fig. 4. Burning locations 3 seconds after the start of the fire.

The simulated fire reaches a HRR of $50 \mathrm{MW}$ in 27 seconds, indicating it develop extremely rapidly as occurred in the real incident. The results of the fire reconstruction are now compared with some observations from the actual incident listed in Table 1. During the incident, just 3 seconds after the start of the fire, the wall of the doorway was involved in the fire as observed from the video images. The ignited PUF at this time in the fire simulation is shown in Fig. 4. Besides a large area on the internal wall and the ceiling of the shooting range, the upper part of the doorway wall is also involved in the fire in the reconstruction. The predicted iso-surface of $2 \mathrm{~m}$ visibility 6 seconds after the start of the fire is shown in Fig. 5. Heavy smoke already reaches the entrance of the shooting range at this time. This is in good agreement with what was recorded on the monitor cameras, where heavy smoke presenting at the entrance of the shooting range at the time. In the fire incident, the cameras stopped working due to the exposure of heavy smoke between 9 and 11 seconds. The locations of the cameras and the area with a predicted visibility of less than $2 \mathrm{~m}$ are depicted in Fig. 6. As seen in the figure, 11 seconds into the fire all the camera locations except No. 1 are engulfed with heavy smoke with a visibility of less than $2 \mathrm{~m}$. 


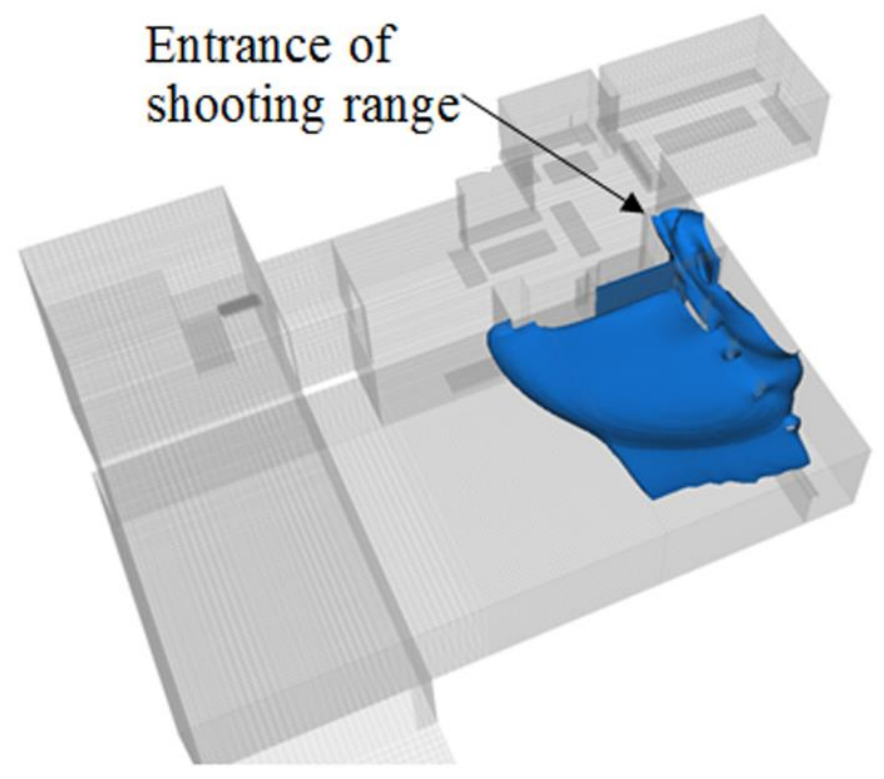

Fig. 5. Predicted iso-surface of $2 \mathrm{~m}$ visibility at 6 seconds.

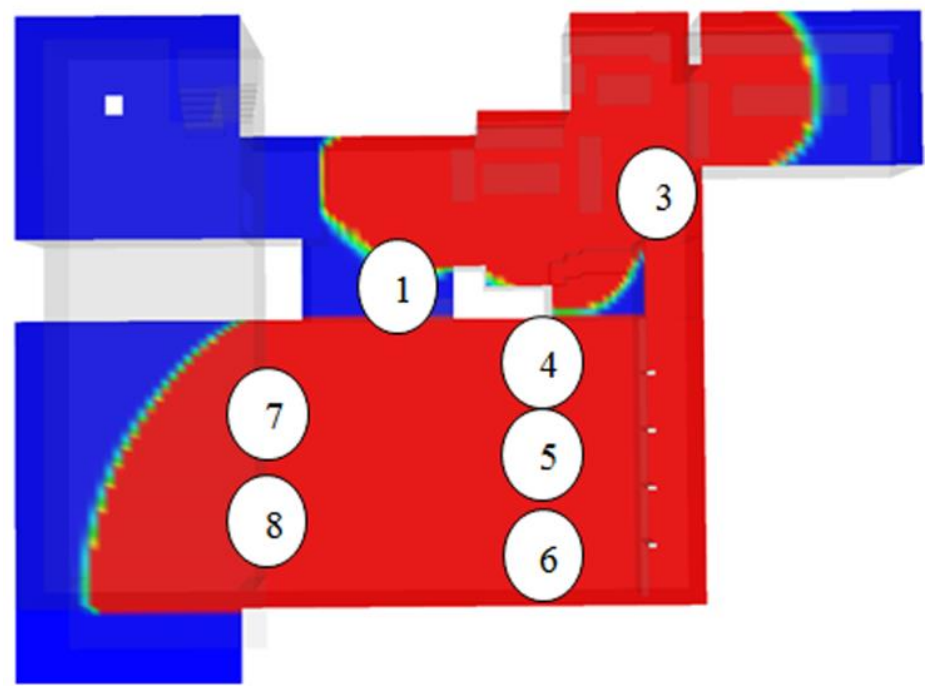

Fig. 6. The area under the ceiling with a visibility of less than $2 \mathrm{~m}$ at 11 seconds (numbers indicate camera positions) in the reconstruction.

The predicted temperatures and $\mathrm{CO}$ concentrations at two locations of interest, near the doorway inside the shooting range and the center of the lounge, are depicted in Fig. 7 and Fig. 8 respectively. The predicted upper layer temperatures rise rapidly 5 seconds after the start of the fire in the shooting range and 10 seconds in the lounge. With atmospheric temperatures above $300{ }^{\circ} \mathrm{C}$ or $\mathrm{CO}$ concentrations above $3 \%$, exposed people will become incapacitated within seconds [11]. The hazard level in the lower layer of a fire enclosure is usually a good indicator of survivability. The times for the lower layer temperature to reach $300{ }^{\circ} \mathrm{C}$ are just 12.5 seconds in the shooting range and 18.5 seconds in the centre of the lounge. Compared with the temperatures, the rapid rise of predicted $\mathrm{CO}$ concentrations has a delay of approximately 5 seconds. The times for the lower layer $\mathrm{CO}$ concentrations to reach $3 \%$ are similar at the two locations, around 27-28 seconds. Therefore, the survival time inside the building is at most half a minute based on the predicted fire hazard levels. 


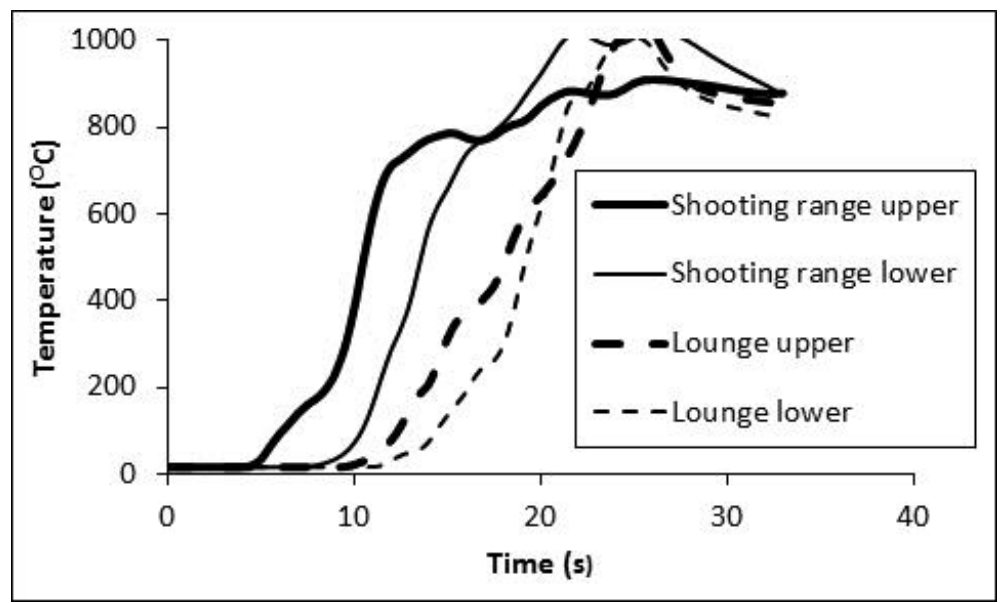

Fig. 7. Predicted temperatures in the upper and lower layers of the shooting range and the center of the lounge.

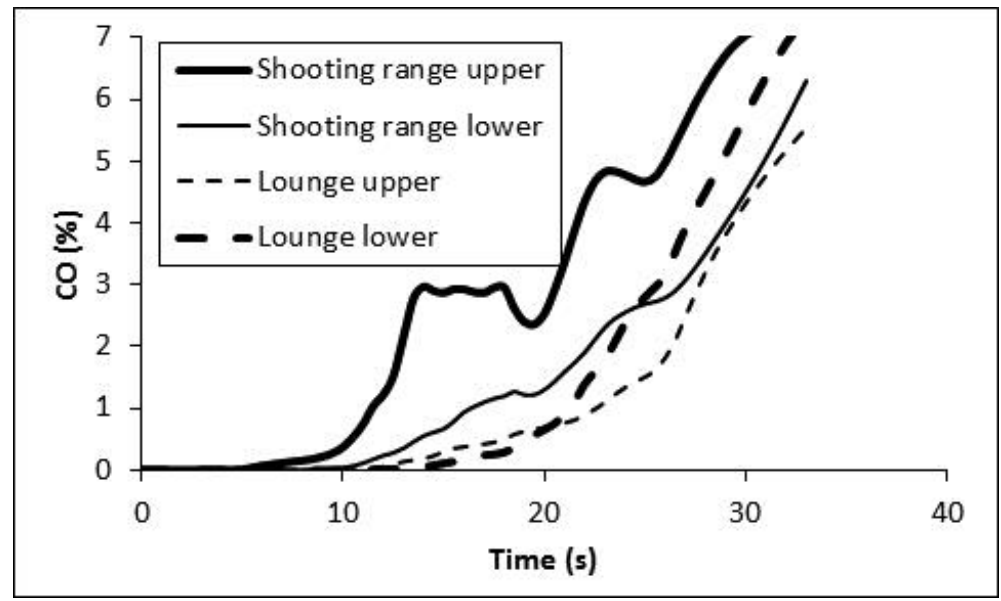

Fig. 8. Predicted CO concentrations in the upper and lower layers of the shooting range and the center of the lounge.

\section{Evacuation Simulation and Results}

The impact of the atmospheric conditions within the fire enclosure on the evacuating occupants are examined using buildingEXODUS [4]. There were 16 people in the premises at the time of the incident, four in the shooting range and 12 in the lounge. The attributes of the 16 people are automatically generated by the simulation tool using default occupant characteristics. Figure 9 shows the locations of the agents at the start of the fire reconstruction. The four agents inside the shooting range are located as described in the investigation report [2] while the agents located in the lounge are randomly assigned their starting locations at the various seats within the area. It was reported that people in the shooting booths noted the fire as early as one second after it started and they commenced their evacuation 2 seconds later. Therefore, the response times for these agents are set to be between 1 and 3 seconds (See Table 3). People in the lounge started to evacuate when they felt vibration under their feet or saw flames suddenly spewing from the shooting range door or heard a booming sound. This occurred between 3 and 6 seconds after the start of the fire. Therefore a response time of between 3 and 4 seconds are assigned for most agents in the lounge except the four agents located in the top right corner. These four agents, they were found dead near their original locations (Fig. 1). It is plausible that the heavy smoke spewing out from the shooting range entrance blocked their evacuation path when they started to move so that they had to stay where they were. Instead of modelling this behaviour, a large response time of 30 seconds is assigned to these agents. A free walking speed of 1.5 $\mathrm{m} / \mathrm{s}$ (the maximum default fast walking speed in buildingEXODUS) is assumed to all the agents. However, if heavy smoke is present in the upper layer, the agents will evacuate by crawling under the smoke. 


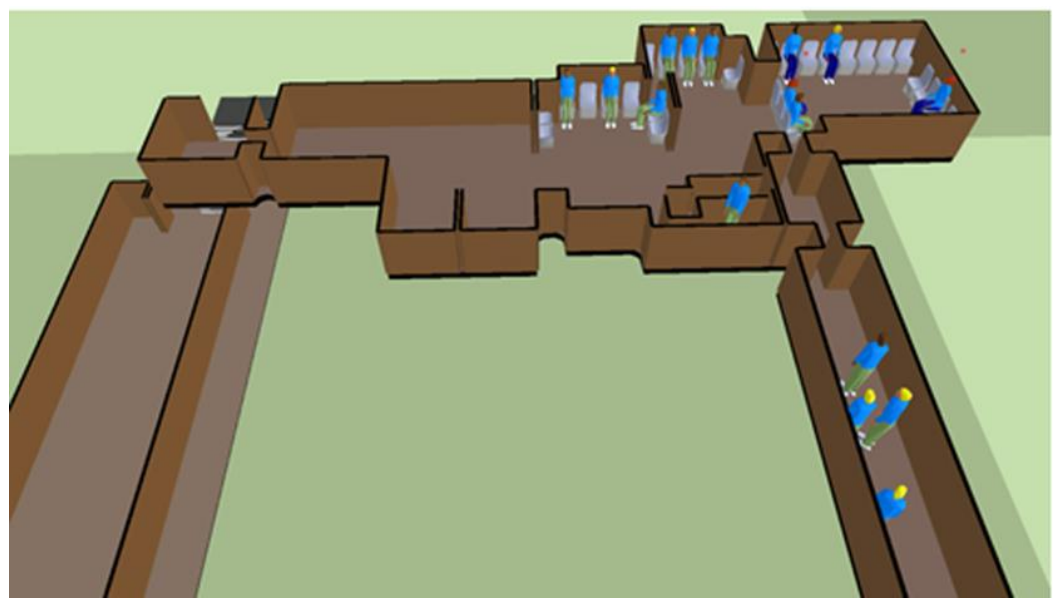

Fig. 9. Starting locations for the population within the fire reconstruction.

Table 3. Agent response times in the reconstruction simulation.

\begin{tabular}{|l|c|c|}
\hline & Response time $(\mathbf{s})$ & Walking speed $(\mathbf{m} / \mathbf{s})$ \\
\hline 4 agents in the shooting range & $1-3$ & 1.5 \\
\hline $\begin{array}{l}\text { 4 agents in the top right corner of } \\
\text { the lounge }\end{array}$ & 30 & 1.5 \\
\hline Remaining 8 agents in the lounge & $3-4$ & 1.5 \\
\hline
\end{tabular}

The evacuation simulation is repeated 100 times and the results presented in Table 4 are the averages for the 100 simulation repetitions. In Table 4, FIH is the measure of the individual's cumulative exposure to radiative and convective heat and FIN is the fractional incapacitating dose of narcotic agents. The evacuation simulations produce very good agreement with the number of fatalities/survivors within the incident. In the incident, there were 15 fatalities and only one survivor. In the reconstruction, the average number of survivors is 1.1. The survivors require an average of 34.9 seconds to exit the enclosure. The sole survivor suffered $45 \%$ flame burn in the incident and the predicted FIH and FIN value for the survivors are 0.14 and 0.01 respectively. The fatalities occur as early as 14.2 seconds after the fire initiation and the last death is at 36.9 seconds with a statistical average of 24.4 seconds within the reconstruction simulations. Only one of the 15 fatalities is due to both the heat exposure and the inhalation of toxic gases. The others are solely the result of the heat exposure. However, the average of FIN values for these fatalities is as high as 0.3. Figure 10 shows the predicted locations of the fatalities resulting from a single evacuation simulation. Among the 15 fatalities, one is near the entrance of the shooting range, four are around the sofas at the top right corner of the lounge, and others are found on their evacuation path from the lounge to the staircases and to the hall on the ground floor. In the real accident, three of the people who died managed to exit the building before they died of their injuries while the others were incapacitated either on the staircase or on the fire floor. Within the reconstruction simulation, while none of the agents that are incapacitated manage to leave the building, several agents mange to reach the ground floor before they are incapacitated. As seen in Fig. 10, which depicts the results from one of the 100 repeat simulations, two agents are incapacitated on the ground floor with one of them almost reaching the exit. Therefore, the predicted distribution of death locations in the reconstruction is comparable to that in the actual incident in Fig. 1.

Table 4. Average evacuation results for the reconstruction simulations.

\begin{tabular}{|l|c|c|}
\hline & Survivor & Fatality \\
\hline Number of agents (person) & 1.1 & 14.9 \\
\hline Evacuation time (s) & 34.9 & 24.4 \\
\hline FIH & 0.14 & 1.0 \\
\hline FIN & 0.01 & 0.30 \\
\hline Time for the first incapacitation (s) & N/A & 14.2 \\
\hline Time for the last incapacitation (s) & N/A & 36.9 \\
\hline
\end{tabular}




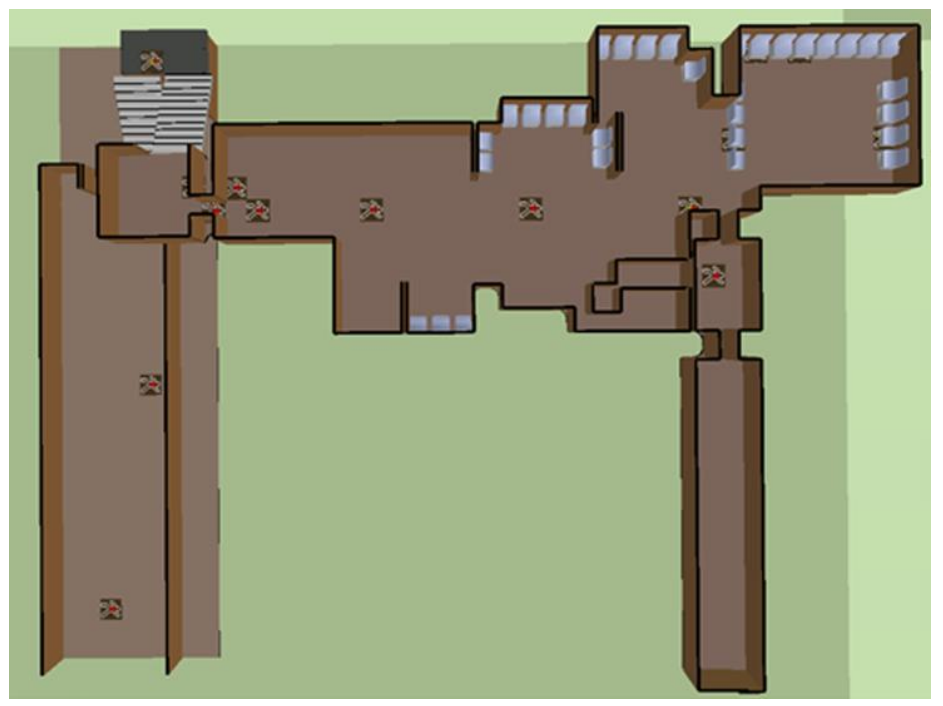

Fig. 10. Predicted death locations from a single evacuation simulation.

\section{RESPONSE TIME SENSITIVITY ANALYSIS}

In the incident reconstruction, the response times are between 1 and 4 seconds for most of the people, which produce only 1.1 survivors on average. In this section, the impact of response time on the evacuation outcome is examined. As seen in Table 5, if all the occupants could start to evacuate when the fire started, there would be an average of 5.7 survivors, 4.6 more than that in the reconstruction. Among the 5.7 survivors, 4 would manage to evacuate without injury. The number of fatalities increases with an increase in response time. If the response times for all occupants were 5 seconds, none of the exposed population would survive. The response time sensitivity analysis demonstrates that in flashover fires seconds can make the difference between life and death. It also indicates that for the given nature of the shooting range fire, fatalities were unavoidable no matter how short the response times.

Table 5. Response times for individuals in the reconstruction.

\begin{tabular}{|c|c|c|c|}
\hline \multirow[t]{2}{*}{ Response time (s) } & \multirow{2}{*}{$\begin{array}{l}\text { Number of } \\
\text { fatalities }\end{array}$} & \multicolumn{2}{|c|}{ Number of survivors } \\
\hline & & Non-injuries & Injuries (FIH>0.01) \\
\hline $\begin{array}{l}1-3 \mathrm{~s} \text { for agents in the shooting } \\
\text { range, } 3-4 \mathrm{~s} \text { for the rest but } 30 \mathrm{~s} \\
\text { for the four in the top right corner }\end{array}$ & 14.9 & 0 & 1.1 \\
\hline $0 \mathrm{~s}$ for all agents & 10.3 & 4.0 & 1.7 \\
\hline $1 \mathrm{~s}$ for all agents & 12.3 & 1.8 & 1.9 \\
\hline $2 \mathrm{~s}$ for all agents & 13.4 & 0.5 & 2.1 \\
\hline $3 \mathrm{~s}$ for all agents & 14.9 & 0 & 1.1 \\
\hline $4 \mathrm{~s}$ for all agents & 15.9 & 0 & 0.1 \\
\hline $5 \mathrm{~s}$ for all agents & 16.0 & 0 & 0 \\
\hline
\end{tabular}

\section{IMPACT OF GUNPOWDER RESIDUE ON FIRE AND EVACUATION}

The extremely rapid propagation of the fire was the main cause of the high loss of life in this incident. The rapid fire development was in turn caused by the PUF on walls with accumulated gunpowder residue. In order to minimise the impact of gunpowder residue on the potential development of fire in the shooting range, it was recommended that a gunpowder cleaning system is installed in all indoor shooting ranges. The shooting range involved in this fire was eventually reopened with such a system installed. Depicted in Figure 11 are the installed gunpowder cleaning gutters within the renovated shooting range. In this section, the effectiveness of the gunpowder cleaning system is investigated to determine if it is sufficient to 
eliminate the risk of fire fatalities developing given a similar fire initiation. This is achieved by performing coupled fire and evacuation simulations with different flame spread rates for the wall PUF. Presented in Table 6 are the four investigated scenarios. Scenario 1 is the incident reconstruction case with an upward flame spread rate of $2 \mathrm{~m} / \mathrm{s}$ representing the PUF with gunpowder residue. Scenario 3 has a flame spread rate of $0.2 \mathrm{~m} / \mathrm{s}$, representing a case with the same PUF as Scenario 1 but without gunpowder residue. The flame spread rates for Scenario 1 and Scenario 3 are estimated from the experimental study in [2]. Scenario 2 has a flame spread rate of $0.4 \mathrm{~m} / \mathrm{s}$ representing a hypothetical case in which the gunpowder is not completely removed and so is comparable with Scenario 3. To demonstrate the importance to fire safety of the selection of sound absorbing material, the flame spread rate in Scenario 4 is set to $0.1 \mathrm{~m} / \mathrm{s}$, half the flame spread rate for the clean PUF investigated in [2], representing a hypothetical 'fire retarded' PUF. In these scenarios, the response times for the occupants are between 3 and 4 seconds, which are the values for most of the occupants in the incident reconstruction.

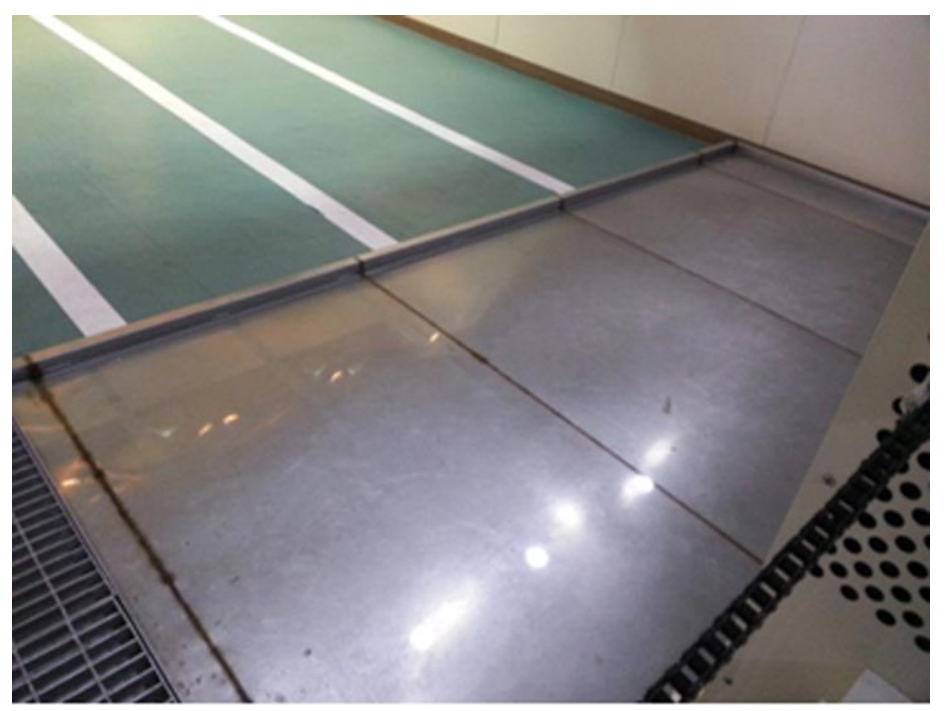

Fig. 11. Gunpowder cleaning gutter in the shooting range.

Table 6. Impact of flame spread rates on evacuation results.

\begin{tabular}{|l|c|c|c|c|}
\hline \multirow{2}{*}{ Scenario } & $\begin{array}{l}\text { Forward } \\
\text { flame spread } \\
\text { rate }(\mathbf{m} / \mathbf{s})\end{array}$ & Fatalities & \multicolumn{2}{|l|}{ Survivors } \\
\cline { 3 - 5 } & 2.0 & 14.9 & Non-injuries & $\begin{array}{l}\text { Injuries } \\
\text { (FIH>0.01) }\end{array}$ \\
\hline $\begin{array}{l}\mathbf{1} \text { (PUF with gunpowder } \\
\text { residue) }\end{array}$ & 0.4 & 3.5 & 11.5 & 1.1 \\
\hline $\mathbf{2}$ (partially cleaned PUF) & 0.2 & 0.1 & 15.6 & 1.0 \\
\hline $\mathbf{3}$ (completely cleaned PUF) & 0.1 & 0 & 16 & 0.3 \\
\hline $\begin{array}{l}\mathbf{4} \text { (hypothetical fire retarded } \\
\text { PUF) }\end{array}$ & & & & 0 \\
\hline
\end{tabular}

The predicted HRRs for the four flame spread scenarios are presented in Fig. 12. The HRRs in Scenario 1 increase rapidly to $70 \mathrm{MW}$ at 34 seconds. The HRRs in other scenarios follow the same trend as seen in Scenario 1 but have various delays. The times for HRRs of the other three scenarios to reach $70 \mathrm{MW}$ are at 44 seconds in Scenario 2, 51 seconds in Scenario 3 and 59 seconds in Scenario 4. 


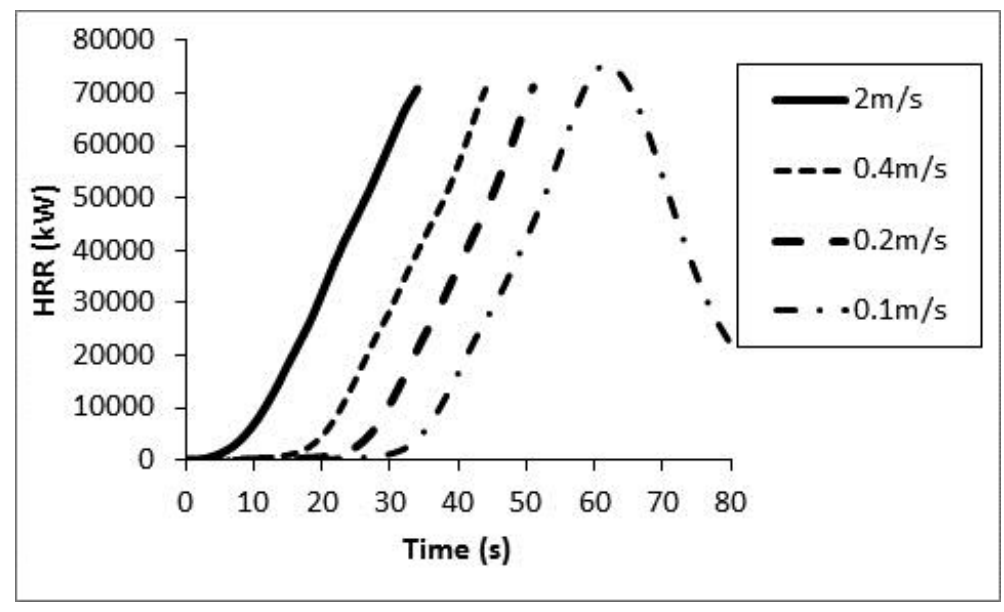

Fig. 12. Predicted HRRs for scenarios with different flame spread rates for different PUF conditions.

As shown in Table 6, in Scenario 3 (the completely cleaned PUF), the fatalities reduce from 14.9 persons in the reconstruction case to just 0.1 persons and almost all the survivors escape uninjured. This result demonstrates that the impact of gunpowder residue on the fire development and the subsequent evacuation is significant. However, Scenario 3 implies a condition in which the PUF wall is completely free of gunpowder residue. This scenario demonstrates that even if the cleaning process is $100 \%$ effective (all the time) it does not completely eliminate potential fire casualties. Furthermore, Scenario 2 demonstrates that if the cleaning process does not completely remove all of the gunpowder residue from the walls, and there is sufficient gunpowder residue to double the flame spread rate compared to that of a completely clean wall (an increase from $0.2 \mathrm{~m} / \mathrm{s}$ to $0.4 \mathrm{~m} / \mathrm{s}$ ) the number of predicted fatalities increases from an average of 0.1 to 3.5 or $3400 \%$. Given that the cleaning process will not keep the walls $100 \%$ clean of gunpowder residue all the time, it is necessary to experimentally investigate the correlation between the amount of gunpowder residue accumulated on the PUF wall and the flame spread rate. This correlation will help to truly understand the efficiency of the gunpowder cleaning system from the point of view of fire safety.

From the above analysis, the wall PUF tested in [2], even without accumulated gunpowder, does not completely remove the risk of injury given a fire. Scenario 4 represents a scenario in which a hypothetical PUF that has been fire retarded is investigated. This hypothetical 'clean' PUF wall sound absorbing material has a flame spread rate that is half of that of the clean PUF wall material tested in [2]. With this flame spread rate, all the agents in the shooting range can safely evacuate without injury. A wide range of PUF are readily available for the selection of sound absorbers. For example, a PUF sound absorber with a flame spread rate of $0.1 \mathrm{~m} / \mathrm{s}$ had been used in the investigation of Rhode Island nightclub fire [15]. Therefore, besides installing a gunpowder cleaning system, the selection of a PUF with good fire resistance for the sound absorbing wall cladding is another important factor to improve the fire safety of the shooting range.

\section{IMPROVING THE FIRE SAFETY OF INDOOR SHOOTING RANGES}

While the response times of occupants exposed to an indoor shooting range fire may significantly affect the outcome of the evacuation, it is not a factor that can be easily controlled. Furthermore, in the incident investigated, even if the response times could be reduced to zero there were still a significant number of casualties. This study has demonstrated that to completely eliminate fire casualties, the flame spread rate of the sound absorption material cladding the walls and ceiling contaminated with gunpowder residue must be below a critical value. In order to improve the fire safety of indoor shooting ranges, the following procedure for selecting wall materials and gunpowder cleaning system is recommended:

1. Perform coupled fire/evacuation simulations to determine the critical flame spread rate for sound absorption materials below which no injury is likely to be incurred in the event of a fire within the shooting range. 
2. Initially select a wall sound absorption material that has a flame spread rate below the critical value identified in 1 .

3. Determine the operational procedure for the chosen gunpowder cleaning system, for example, identify a permitted maximum amount of gunpowder residue that can remain on the selected material and the required cleansing frequency to ensure that gunpowder residue does not exceed critical levels.

4. Experimentally determine the flame spread rate of the selected wall material with the permitted maximum amount of gunpowder residue. If the flame spread rate is greater than the critical flame spread rate identified in 1, consider either selecting a different wall material or change the operation of the gunpowder cleaning system, for example, shorten the interval between cleaning cycles - thereby reducing the permitted maximum amount of gunpowder residue on the material.

\section{CONCLUSIONS}

SMARTFIRE and buildingEXODUS simulation tools have been used to numerically investigate the tragedy of the Pusan shooting range fire of 2009 in which 15 people lost their lives and one person was severely injured. The first part of the analysis involved reconstructing the shooting range fire. In the reconstruction simulation, parameters in the fire and evacuation models are adjusted to produce predictions to the smoke movement, burning locations, the number of fatalities and death locations as close as possible to the actual incident outcomes. Then the impacts of occupants' response times and the flame spread rates for polyurethane foam on survivability are examined.

The key findings from this work are:

- Coupled fire and evacuation analysis technique is capable of reconstructing the complex nature of the shooting range fire and resulting survivability.

- Occupants' response times are essential for safe evacuation in any fire situation. However, for the given nature of the investigated shooting range fire, fatalities were unavoidable no matter how quickly the occupants responded. Furthermore, it is unlikely that anyone would have survived this fire if their response time was greater than 5 seconds.

- Accumulated gunpowder residue on the polyurethane foam is the most important factor for the high number of fatalities in this incident. The number of fatalities could be reduced from an average of 14.9 in the reconstruction to just 0.1 if $100 \%$ of the accumulated gunpowder residue could have been removed from the polyurethane foam.

- However, cleaning the gunpowder residue from the polyurethane foam walls is insufficient to completely avoid fire related casualties. To completely eliminate fire casualties, the flame spread rate of the $100 \%$ cleaned polyurethane foam sound absorbing wall cladding should be $50 \%$ less than that for the tested material.

This study suggests that appropriate polyurethane foam with low flame spread rates should be selected for sound absorbing wall cladding materials and an effective gunpowder cleaning system and associated cleaning protocol is essential to reduce the likelihood of incurring casualties in the event of a fire in indoor shooting ranges. The results of the coupled fire and evacuation simulations also suggest that it is essential to determine the effectiveness of the gunpowder cleaning system in removing gunpowder residue from the walls to reliably estimate the impact of the cleaning system on fire safety. Associated with this, it is necessary to conduct experiments to examine the impact of the amount of gunpowder residue on flame spread for the selected polyurethane foam wall cladding.

\section{REFERENCES}

[1] Park W., Fire at an Indoor Shooting Range in Busan I. Fire Reconstruction, J. of Korean Institute of Fire Sci. \& Eng., 24:114-119.

[2] Cho Y., Kong Y., Sa S., Choi C., Kim D., Goh J., Park N., and Choi D., Forensic analysis on the cause and origin of the 2009 indoor shooting range fire in Pusan, Korea, Fire Technology, 51 (2015): 1113-1128, http://dx.doi.org/10.1007/s10694-014-0440-3 
[3] Wang Z., Jia F. and Galea E. R., "Fire and evacuation simulation of the fatal 1985 Manchester Airport B737 fire", Proceedings of the 5th international symposium, Human Behaviors in Fire 2012, Interscience Communications Ltd., London, 2012, pp. 159-170.

[4] Galea E. R., Lawrence P. J., Filippidis L., Blackshieldsand D. and Cooney D., buildingEXODUS version 6.1: User Guide and Technical Manual, University of Greenwich, UK, 2014.

[5] Ewer J., Jia F., Grandison A., Galea E. R. and Patel M. K., SMARTFIRE V4.1 User Guide and Technical Manual, Fire Safety Engineering Group, University of Greenwich, UK, 2008.

[6] Jia F., Patel M. P., Galea E. R., Grandison A. and Ewer J., CFD Fire Simulation of the Swissair Flight 111 In-flight Fire - Part II: Fire Spread within the Simulated Area, The Aeronautical Journal of the Royal Aeronautical Society, 110:303-314, http://dx.doi.org/10.1017/s0001924000013178

[7] Galea E. R., Wang Z., Veeraswamy A., Jia F., Lawrence P. J. and Ewer J., "Coupled fire/evacuation analysis of station nightclub fire", Fire Safety Science -- Proceedings of the ninth International Symposium, International Association for Fire Safety Science, 2008, pp. 465-476.

[8] Galea E. R., Filippidis L., Wang Z., and Ewer J., Fire and evacuation analysis in BWB aircraft configurations: computer simulations and large-scale evacuation experiment, The Aeronautical Journal of the Royal Aeronautical Society, 114:271-277, http://dx.doi.org/10.1017/s0001924000003717

[9] Hu X., Wang Z., Jia F. and Galea E. R., Numerical investigation of fires in small rail car compartments, Journal of Fire Protection Engineering, 22:245-270, http://dx.doi.org/10.1177/1042391512459640

[10] Wang Z., Jia F., Galea E. R., Computational fluid dynamics simulation of a post-crash aircraft fire test, Journal of Aircraft, 50:164-175, http://dx.doi.org/10.2514/1.c031845

[11] D. A. Purser, "Toxicity Assessment of Combustion Products", The SFPE Handbook of Fire Protection Engineering (3rd Edition), Dilenno, P.J. (ed.), National Fire Protection Association, Quincy, MA 02269, 2002, p. 2/83.

[12] Jin T., and Yamada T., Irritating Effects From Fire Smoke On Visibility, Fire Science And Technology, 5:79-90, http://dx.doi.org/10.3210/fst.5.79

[13] Magnussen B. F. and Hjertager B. H., "On mathematical modelling of turbulent combustion with special embassies on soot formation and combustion", 16th Symp. (Int.) on Combustion, the Combustion Institute, 1977, pp. 719-729, http://dx.doi.org/10.1016/s0082-0784(77)80366-4

[14] Tewarson A., "Generation of heat and chemical compounds in fires", The SFPE Handbook of Fire Protection Engineering ( $\left.2^{\text {nd }} e d\right)$, DiNenno P.J. (ed.), National Fire Protection Association, Quincy, MA 02269, 1995, p. 3.53.

[15] Grosshandler W., Bryner N., Madrzykowski D. and Kuntz K., "Report of the technical investigation of the station nightclub fire", National Institute of Standards and Technology, Report NIST NCSTAR 2: Vol. I-II , Gaitherburg, MD., USA, 2005, 250 p. (I), 417 p. (II). 